University of Wollongong

Research Online

Faculty of Engineering and Information

Faculty of Engineering and Information

Sciences - Papers: Part B

Sciences

2016

Impacts of redox-mediator type on trace organic contaminants degradation by laccase: Degradation efficiency, laccase stability and effluent toxicity

Bradley Ashe

University of Wollongong

Luong Nguyen

University of Wollongong, luong@uow.edu.au

Faisal I. Hai

University of Wollongong, faisal@uow.edu.au

Duu-Jong Lee

National Taiwan University, djlee@ntu.edu.tw

Jason P. Van De Merwe

Griffith University

See next page for additional authors

Follow this and additional works at: https://ro.uow.edu.au/eispapers1

Part of the Engineering Commons, and the Science and Technology Studies Commons

Research Online is the open access institutional repository for the University of Wollongong. For further information contact the UOW Library: research-pubs@uow.edu.au 


\title{
Impacts of redox-mediator type on trace organic contaminants degradation by laccase: Degradation efficiency, laccase stability and effluent toxicity
}

\author{
Abstract \\ This study compares the effectiveness of seven redox-mediating compounds namely, \\ 1-hydrozybenzotriazole (HBT), N-hydroxyphthalimide (HPI), 2,2,6,6-Tetramethyl-1-piperidinyloxy (TEMPO), \\ violuric acid (VA), syringaldehyde (SA), vanillin (VA), and 2,2'-azino-bis(3-ethylbenzothiazoline-6-sulfonic \\ acid) diammonium salt (ABTS), which follow distinct oxidation pathways, for the degradation of trace \\ organic contaminants (TrOCs). These redox-mediators were investigated for improved degradation of \\ four TrOCs showing resistance to degradation by crude laccase from the white-rot fungus Pleurotus \\ ostreatus. ABTS and VA achieved the highest degradation of the phenolic compounds (i.e., oxybenzone \\ and pentachlorophenol), whereas the non-phenolic compounds (i.e., naproxen and atrazine) were best \\ removed using VA or HBT. This implies that the non-phenolic compounds are more effectively removed by \\ the radical species generated by the $\mathrm{NeOH}$ type mediators (i.e., VA and $\mathrm{HBT}$ ), while removal of the \\ phenolic compounds may depend more on the stability and the redox potential of the radicals generated \\ from the mediator, irrespective of the type. Notably, enzyme stability was greatly affected by the $\mathrm{NeOH}$ \\ type mediators but it was compensated by their rapid degradation capacity. Overall, VA and $\mathrm{HBT}(\mathrm{NeOH}$ \\ type) appear to be the best mediators for enhanced degradation of the selected compounds without \\ causing significant toxicity in the effluent.

\section{Disciplines} \\ Engineering | Science and Technology Studies

\section{Publication Details} \\ Ashe, B., Nguyen, L. N., Hai, F. I., Lee, D., Van De Merwe, J. P., Leusch, F. D. L., Price, W. E. \& Nghiem, L. D. \\ (2016). Impacts of redox-mediator type on trace organic contaminants degradation by laccase: \\ Degradation efficiency, laccase stability and effluent toxicity. International Biodeterioration and \\ Biodegradation, 113 169-176.
}

\section{Authors}

Bradley Ashe, Luong Nguyen, Faisal I. Hai, Duu-Jong Lee, Jason P. Van De Merwe, Frederic Leusch, William E. Price, and Long D. Nghiem 


\section{Highlight}

- TrOC removal performance of laccase - mediator systems is mediator dependent

- Non-phenolic compounds are more effectively removed by the N-OH type mediators

- Phenolics removal depend more on stability/redox potential of the mediator radicals

- Higher concentrations of mediators result in faster destabilisation of laccase

- Violuric acid degraded phenolic/non-phenolic TrOC w/out raising effluent toxicity 


\section{Impacts of redox-mediator type on laccase degradation of trace organic contaminants:}

Degradation efficiency, laccase stability and effluent toxicity

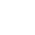

Revised manuscript Submitted to

International Biodeterioration \& Biodegradation (CESE special issue)

March, 2016
Bradley Ashe ${ }^{\mathrm{a}}$, Luong N. Nguyen ${ }^{\mathrm{a}}$, Faisal I. Hai ${ }^{\mathrm{a}}$, Duu-Jong Lee ${ }^{\mathrm{b}}$, Jason P. van de Merwe ${ }^{\mathrm{c}}$, Frederic D.L. Leusch ${ }^{c}$, William E. Price ${ }^{\mathrm{d}}$, and Long D. Nghiem ${ }^{\mathrm{a}}$

(1)

(1)

(1)

2

${ }^{a}$ Strategic Water Infrastructure Laboratory, School of Civil, Mining and Environmental Engineering, University of Wollongong (UOW), NSW 2522, Australia

${ }^{\mathrm{b}}$ Department of Chemical Engineering, National Taiwan University, Taipei, Taiwan.

${ }^{\mathrm{c}}$ Smart Water Research Centre, Australian Rivers Institute, School of Environment, Griffith

${ }^{\mathrm{d}}$ Strategic Water Infrastructure Laboratory, School of Chemistry, UOW, NSW 2522, Australia 8

9

0

21

2

* Corresponding author: Faisal I. Hai, E-mail: faisal@uow.edu.au, Ph: + 61242213054

24

5

6




\section{Abstract}

28 This study compares the effectiveness of seven redox-mediating compounds namely, 1hydrozybenzotriazole (HBT), N-hydroxyphthalimide (HPI), 2,2,6,6-Tetramethyl-1piperidinyloxy (TEMPO), violuric acid (VA), syringaldehyde (SA), vanillin (VA), and 2,2'azino-bis(3-ethylbenzothiazoline-6-sulfonic acid) diammonium salt (ABTS), which follow distinct oxidation pathways, for the degradation of trace organic contaminants (TrOCs). These redox-mediators were investigated for improved degradation of four TrOCs, namely, oxybenzone, pentachlorophenol, naproxen and atrazine, which showed resistance to degradation by crude laccase harvested from the white-rot fungus Pleurotus ostreatus. A series of screening tests showed that ABTS, VA and HBT were the most efficient mediators for degradation of the

37 selected TrOCs. ABTS and VA achieved the highest degradation of the phenolic compounds (i.e., oxybenzone and pentachlorophenol), whereas the non-phenolic compounds (i.e., naproxen and atrazine) were best removed using VA or HBT. This implies that the non-phenolic compounds are more effectively removed by the radical species generated by the N-OH type mediators (i.e., VA and HBT), while removal of the phenolic compounds may depend more on

42 the stability and the redox potential of the radicals generated from the mediator, irrespective of 43 the type. Notably, enzyme stability was greatly affected by the N-OH type mediators but it was compensated by their rapid degradation capacity. Overall, VA and HBT (N-OH type) appear to be the best mediators for enhanced degradation of the selected compounds without causing 46 significant toxicity in the effluent.

47 Keywords: Laccase degradation; Redox mediator; Trace organic contaminant; Effluent toxicity 


\section{Introduction}

50 Laccase (EC 1.10.3.2) is a type 1 (blue) copper oxidase. It is widely distributed among white rot fungi, which are responsible for the degradation of complex organic polymeric lignins in nature (Yang et al., 2013). Laccase predominantly attacks the phenolic moieties in lignin, catalysing a one-electron oxidation via phenoxyl radicals. Laccase has been used in various industries such as textiles, pulp and paper, food manufacture and in remediation processes especially in the degradation of phenols and anilines (Hai et al., 2013; Witayakran and Ragauskas, 2009). In recent years, the removal of trace organic contaminants (TrOCs) from water and wastewater by laccase has received increasing attention. TrOCs are detected in various water bodies at low concentrations (i.e., a few ng/L). Many TrOCs are ineffectively removed by the conventional wastewater treatment processes (Hai et al., 2014; Luo et al., 2014) and pose a threat to aquatic ecosystems and to the safety of drinking water resources.

The ability of laccase to degrade TrOCs has been shown for several subgroups such as industrial chemicals (Gros et al., 2014), anti-inflammatory drugs (Tran et al., 2010), antibiotics (Auriol et al., 2007; Weng et al., 2012), personal care products e.g., UV filters (Garcia et al., 2011) and pesticides (Majeau et al., 2010). The oxidative efficiency of laccases depends on the redox potential difference between the reducing substrate and type 1 copper in laccase. Given the range of redox potentials that laccases from different fungi possess $(0.17-0.80 \mathrm{~V})$ (Cañas and Camarero, 2010), non-phenolic substrates are often not amenable to direct oxidation by laccase. laccase. Particularly, the distribution of functional groups within the TrOC has a large influence on the efficiency of the oxidation process by laccase (Yang et al., 2013). There are two categories of functional groups: i) electron donating functional groups (EDGs) including hydroxyl and amine that are strong activating groups, meaning that compounds containing these groups are more susceptible to electrophilic attack; and ii) electron withdrawing functional groups (EWGs) such as nitro, halogen, carboxyl and amide groups that are strong deactivating groups making the oxidation of these compounds much slower and more complicated (Yang et al., 2013). Some TrOCs may not be directly oxidized by laccase. These include bulky compounds that cannot access the laccase-active site and those with a high redox potential. This limitation can be overcome by adding a small molecular weight redox-mediating substrate of laccase whereby highly reactive radicals generated due to oxidation of the mediator by laccase 
can in turn degrade the target compound of interest. This mechanism is analogous to the natural lignocellulose biodegradation by white- and brown- rot fungi, which produce reactive oxygen species (e.g., hydroxyl, peroxyl and hydroperoxyl radicals) to initiate the biodegradation of biopolymers found in wood (Hammel et al., 2002).

Three major mechanisms by which a mediator can oxidize a substrate have been reported in the literature: hydrogen atom transfer, electron transfer and ionic mechanisms (Astolfi et al., 2005). Mediators differ from each other in terms of optimal reaction conditions and in specificity towards a given target compound (Baiocco et al., 2003). Previous studies have focused on performance comparison of different laccase - mediator combinations for degradation of dyes (Khlifi et al., 2010; Mendoza et al., 2011) and TrOCs (Garcia et al., 2011; Jeon et al., 2008). However, critical aspects such as laccase stability and the treated effluent toxicity are often overlooked or not comprehensively covered. A study with such a focus would help identify the type and dose of mediators that improve TrOC removal while minimizing effluent toxicity and laccase inactivation.

This study aims to compare the effectiveness of seven selected redox-mediators, representing three different oxidative mechanisms, for enhancing the oxidation of four resistant TrOCs by laccase. The performance of laccase with different mediators was systematically compared particularly focusing on laccase stability, TrOC removal efficiency, and effluent toxicity to pinpoint the best mediator. A series of batch tests with crude laccase preparation from white-rot fungi Pleurotus ostreatus were used to evaluate the impact of mediator concentrations, types and reaction times.

\section{Materials and methods}

\subsection{Crude laccase preparation}

Erlenmeyer flasks $(250 \mathrm{~mL})$ containing $50 \mathrm{~mL}$ of malt extract at a concentration of $5 \mathrm{~g} \mathrm{~L}^{-1}$ were inoculated with the white-rot fungus $P$. ostreatus (ATCC 34675). The $\mathrm{pH}$ of the solution was adjusted to 4.5 and the culture incubated on a rotary shaker at $70 \mathrm{rpm}$ and $28{ }^{\circ} \mathrm{C}$ for one week. The fungus secreted extracellular laccase into the media and this crude enzyme extract was separated from the biomass before storing in sterilized bottles at $4{ }^{\circ} \mathrm{C}$. 
109 Four TrOCs namely oxybenzone, pentachlorophenol, atrazine and naproxen were selected based on their widespread occurrence in water and wastewater and their resistance to degradation by

111 laccase in previous studies (Nguyen et al., 2014b; Yang et al., 2013). These compounds were 112 selected to facilitate a systematic investigation of the effect of mediator addition. The 113 physicochemical properties of these compounds are summarized in Supplementary Data Table 114 S1.

115 A range of mediators, including 1-hydroxybenzotriazole (HBT), 2,2'-Azino-bis(3116 ethylbenzothiazoline-6-sulfonic acid) diammonium salt (ABTS), syringaldehyde (SA), (2,2,6,6-

117 Tetramethylpiperidin-1-yl)oxy (TEMPO), Violuric acid (VA), Vanillin (VAN) and N118 Hydroxyphthalimide (HPI) were used to compare the relative efficiency of mediators at aiding 119 the removal of target contaminants. As shown in Table 1, these mediators follow three different 120 mechanisms: hydrogen atom transfer (SA, HBT, VA, VAN and HPI), electron transfer (ABTS) 121 and ionic mechanism (TEMPO).

\section{[TABLE 1]}

$123 \quad 2.3$ Experimental protocol

124 For the initial screening of the mediators, crude laccase extract $(5 \mathrm{~mL})$ with an initial activity of $12552 \pm 2(n=2) \mu \mathrm{M}_{(\mathrm{DMP})} \min ^{-1}$ was added to $10 \mathrm{~mL}$ test tubes. Working solution, comprising the 126 four TrOCs, was added to the test tubes containing crude enzyme to yield a final concentration of $127500 \mu \mathrm{g} \mathrm{L}^{-1}$ of each compound. Selected mediators were added to the solutions separately to 128 produce final mediator concentrations of $1 \mathrm{mM}$. Controls included TrOC solution in Milli-Q 129 water and TrOC solution and enzyme solution without mediator. Tests were conducted in 130 duplicate. Test tubes were sealed and incubated on a rotary shaker at $70 \mathrm{rpm}$ and $25^{\circ} \mathrm{C}$ for $24 \mathrm{~h}$.

131 The three mediators that exhibited the greatest TrOC removal in the mediator screening 132 experiments (i.e., ABTS, VA and HBT) were selected for assessment of impact of incubation 133 time (2, 4, 8 and $24 \mathrm{~h})$ and mediator concentration $(0.05,0.1,0.25,0.5$ and $1 \mathrm{mM})$. These tests 134 were conducted in the same way as described above. 


\subsection{Analytical methods}

Laccase activity was assayed by recording the change in absorbance (468 $\mathrm{nm}$ ) due to oxidation of 2,6-dimethoxyl phenol (DMP) in the presence of sodium citrate ( $\mathrm{pH} 4.5)$. Enzymatic activity was calculated using a molar extinction coefficient of $49.6(\mathrm{mM} \mathrm{cm})^{-1}$ and expressed in $\mu \mathrm{M}_{(\mathrm{DMP})}$ $\min ^{-1}$. The redox potential of the laccase solution before and after mediator addition was measured utilizing an oxidation-reduction potential meter (WP-80D dual pH-mV meter, Thermo Fisher Scientific, Australia). Toxicity of untreated and treated media was analysed in duplicate by measuring inhibition of luminescence of naturally luminescent bacterium Photobacterium leiognathi, and expressed as relative Toxic Unit (rTU), the reciprocal of the $\mathrm{IC}_{20}$ value of the inhibition of luminescence vs. concentration curve (van de Merwe and Leusch, 2015). The concentration of the four TrOCs utilized in this study (i.e., pentachlorophenol, oxybenzone, naproxen and atrazine) was measured by an HPLC-UV-vis detector system (Shimadzu, Japan) following a previously reported method (Nguyen et al., 2014a).

\section{Results and discussion}

\subsection{Removal of TrOCs by laccase}

Substrate degradation by laccase is limited by two factors, principally, the availability of strong EDG within its structure, and the redox potential of that particular type of laccase. Also, steric shielding from EWG may prevent electron abstraction from occurring. Hence, this section explains enzymatic degradation of the selected TrOCs based on their molecular structures and the presence of EDGs and EWGs (Yang et al., 2013). Results show low laccase-catalyzed degradation (15-23\%) of the four TrOCs (Figure 1).

Among the tested TrOCs, oxybenzone was removed with the highest efficiency $(23 \pm 2 \%$, $(n=2))$. Oxybenzone contains two EDGs, namely, methoxy and hydroxyl groups (Supplementary Data Table S1). However, the relatively low removal rates may be explained by the presence of carbonyl (an EWG) in its structure. Pentachlorophenol was also poorly removed by laccase (23 \pm $8 \%,(n=2))$. The presence of five chlorine atoms in its ring creates a highly stable compound that is resistant to degradation by laccase. Even though pentachlorophenol contains the strong EDG hydroxyl, the steric effects of the chlorine groups prevent the hydroxyl group from gaining access to the active sites of the enzyme (Hai et al., 2011; Yang et al., 2013). Our observation regarding the low removal of oxybenzone and pentachlorophenol is in line with literature. For 
165

166

167

168

169

170

171

172

173

174

175

176

177

178

179

180

181

182

183

184

185

186

187

188

189

190

191

192

193

194

example, Garcia et al. (2011) reported that laccase from Trametes versicolor could not oxidize oxybenzone. Jeon et al. (2008) observed no removal of pentachlorophenol by laccase derived from Ganoderma lucidum. In a contrasting study by Ullah et al. (2000), 60\% removal of pentachlorophenol was observed by laccase from Coriolus versicolor. Ullah et al. (2000) did not report the redox potential of the laccase that they used, thus it could not be confirmed whether the laccase from $P$. ostreatus as used in this study $(0.28 \mathrm{~V})$ had a lower redox potential. However, it is likely that the difference in redox potential between the substrate and the specific laccase used was responsible for different levels of pentachlorophenol degradation.

The pesticide, atrazine, was also poorly removed, showing only $15 \pm 6 \%,(n=2)$ degradation. Even though atrazine contains methyl and amine EDGs, the presence of the strong EWG chlorine hinders laccase-catalyzed degradation (Nguyen et al., 2014a). The low removal of naproxen $(15 \pm 4 \%)$ can be attributed to the presence of the EWG carboxyl, and the absence of any strong EDGs. The ether group present in this compound is a weak EDG, which makes naproxen a highly stable compound, able to resist enzymatic oxidation. For example, MarcoUrrea et al. (2010) also observed less than $10 \%$ removal of naproxen by laccase of T.versicolor.

Overall, the low removal of the tested TrOCs necessitates the addition of mediators in order to enhance their degradation. The enzyme activity remained virtually unchanged throughout the course of the experiment which demonstrates that these four contaminants do not have an adverse effect on the stability of the enzyme at the concentrations tested.

\subsection{Mediator screening}

Redox mediators can act as an electron shuttle between laccase and the substrate in order to overcome steric hindrances and kinetic limitations of laccase. This mechanism involves the oxidation of the mediator compounds by laccase, which results in the production of radical species that possess higher oxidative capacity towards the substrate than the laccase itself. There are a number of variables that influence this process including molecular structure of the contaminant, mediator type and concentration, and the redox potential of the laccase. The type of mediator and its mechanism of action is known to have a significant impact on TrOC degradation (Kurniawati and Nicell, 2007). As noted in Section 2.2, there are three recognized degradation mechanisms, namely, hydrogen atom transfer, electron transfer and ionic mechanism. The mediators SA, HBT, HPI, VAN, and VA have all been shown to use hydrogen 
atom transfer, whilst ABTS and TEMPO follow the electron transfer and ionic mechanisms, respectively.

Following mediator addition, oxybenzone and pentachlorophenol experienced the highest removal efficiencies, most probably because both these TrOCs are phenolic compounds. In comparison, atrazine and naproxen (which are both non-phenolics) experienced slightly lower removal rates (Figure 1) when mediators were added.

High oxybenzone removal (>70\%) was achieved by three mediators, specifically, HBT, VA and ABTS. Among these, VA and ABTS were able to achieve almost complete removal of oxybenzone (98\% and 96\%, respectively). The high laccase-catalyzed degradation of oxybenzone due to ABTS addition agrees well with the findings of a study by Garcia et al. (2011) who, however, used laccase derived from T. versicolor. Notably, both VA and HBT reduce to aminoxyl radicals whereas ABTS reduces to $\mathrm{ABTS}^{+\bullet}$ radicals. The distinct radicals produced by the laccase-catalyzed oxidation of ABTS and VA appear to have an important influence on the degradation of oxybenzone.

Pentachlorophenol was removed by around $75 \%$ by the aminoxyl radicals produced via oxidation of the mediators HBT and VA by laccase. However, the best removal of pentachlorophenol (83\%) was achieved with ABTS. The observed high degradation of pentachlorophenol by laccase due to mediator dosing is in agreement with the findings of another study by Nguyen et al. (2014b), who, however, studied only HBT and used laccase from T. versicolor.

Atrazine degradation was best achieved with the addition of VA, which increased the removal efficiency from 24 to $73 \%$ upon mediator addition. In the case of atrazine, VA was discernibly far better than any other mediator. SA, HBT, VAN and ABTS were also capable of improving the degradation of atrazine, however, removal efficiencies ranged from only $38-50 \%$ when these mediators were added. Particularly, although HBT, HPI and VA are all N-OH type mediators, higher removal yields were achieved by the laccase -VA system. These results suggest that the affinity between the aminoxyl radicals from VA and atrazine play an important role in its degradation. The presence of different substituent groups in HBT, HPI and VA may have influenced the chemical properties of generated radicals (e.g., polarity), consequently contributing to the difference in removal efficiency (Baiocco et al., 2003; d'Acunzo and Galli, 2003). 
225

226

227

228

229

230

231

232

233

234

235

236

237

238

239

240

241

242

243

244

245

246

247

248

249

250

251

252

253

ABTS achieved the best removal (77\%) of naproxen. This was closely followed by VA, which removed $63 \%$ of the initial concentration of naproxen. The N-OH type mediators, HBT and HPI as well as the methoxyphenol mediator, VAN, were all able to improve the efficiency of naproxen degradation by laccase, however, the removal rates were still very low (36-39\%). The $\mathrm{ABTS}^{+\bullet}$ radicals showed the greatest naproxen degradation potential, possibly due to the different mechanism of oxidation (i.e., electron transfer). Laccase-mediated naproxen degradation has been studied previously by Lloret et al. (2013), who also observed that ABTS was the most efficient mediator compared to the $\mathrm{N}-\mathrm{OH}$ type mediators HBT and SA. It is noted that the reactivity of mediators towards substrates in the laccase - mediator system varies depending on the functional groups in the substrates. For example, laccase-ABTS system is effective on benzyl alcohols but not on benzylic ether structures (Baiocco et al., 2003). On the other hand, HBT and VA are more efficient in degrading methyl veratryl ether (Camarero et al., 2005).

The initial screening of the mediators showed that the increase in TrOC degradation varied between mediator type, and that there was no distinct broad-spectrum mediator. Of the seven mediators tested, HBT, VA and ABTS achieved the highest removal of TrOCs.

\section{[FIGURE 1]}

In absence of any mediators, no loss in laccase activity was observed during the $24 \mathrm{~h}$ period of incubation. However, mediator addition to laccase solution caused some loss of laccase activity, and the degree of inhibition was different for different mediators (Figure 2). Interestingly, when TEMPO, HPI, SA or VAN was added separately, low removals of TrOCs were achieved, but the loss of laccase activity was also negligible (between 5-10\%). On the other hand, a significant loss in laccase activity was observed due to the addition of VA, HBT or ABTS, which in fact outperformed the other mediators in terms of TrOC degradation. The results from this study are in line with the study by Fillat et al. (2010) where HBT showed the highest laccase inactivation compared with the methoxyphenol type mediators, namely, SA, acetosyringone, P-coumaric acid and methyl syringate. Garcia et al. (2011) achieved 90\% removal of oxybenzone by laccase ABTS system with $64 \%$ loss of laccase activity, whereas laccase - P-coumaric acid system yielded 5\% removal of oxybenzone with insignificant denaturation of laccase. 
Increase in the redox potential of the reaction mixture is thought to be one of the reasons for the enhanced TrOC degradation by laccase-mediator systems. In this study, a mediator-specific increase in the redox potential of the laccase solution was observed after mediator addition (Figure 2). Among the N-OH type mediators HBT, HPI and VA, the highest increase in redox potential was achieved by VA, followed by HBT and HPI. This could explain the higher removal yields by laccase -VA system as noted earlier. However, it is noteworthy that improvement in TrOC removal did not always correlate with increase in redox potential. For example, SA and VA produced similar levels of redox potential increase, but VA achieved much better removal of TrOCs. Results here demonstrate that for an efficient laccase-mediator system, the redox potential is a contributing but not the sole factor. Overall, the mediators HBT, VA and ABTS that showed the greatest enhancement of TrOC degradation were used in subsequent investigations to further evaluate their effectiveness at different concentrations and reaction times.

[FIGURE 2]

\subsection{TrOC removal by laccase - mediator system}

\subsubsection{Effect of mediator concentrations}

Figure 3 depicts the relationship between mediator concentration and TrOC removal. It can be seen that TrOC removal increased with mediator concentration up until a threshold value, beyond which no significant enhancement in TrOC degradation occurred. The literature shows that this threshold value is dependent on factors such as mediator type, contaminant type and source of enzyme. For example, by increasing the concentration of HBT from 0.2 to $2 \mathrm{mM}$, Mizuno et al. (2009) achieved gradual increase in iso-butylparaben and n-butylparaben removal, but no further improvement was observed beyond $2 \mathrm{mM}$. By contrast, Lloret et al. (2010) obtained 40-80\% removal of diclofenac with SA concentrations ranging from 0.1 to $0.5 \mathrm{mM}$, while complete removal was achieved at $1 \mathrm{mM}$.

In this study, oxybenzone was completely removed with the addition of either VA or ABTS at 1 $\mathrm{mM}$. At the same dose of VA or ABTS, a slightly lower degradation (i.e., maximum 80\%) was achieved for the other phenolic compound pentachlorophenol. VA and ABTS were significantly 
more effective than HBT at enhancing oxybenzone degradation regardless of concentration (Figure 3). On the other hand, the N-OH type mediators (i.e., VA and HBT) were less effective at lower concentrations for pentachlorophenol degradation when compared to ABTS. However, at higher concentrations, all of the mediators performed similarly.

Atrazine was the most recalcitrant compound tested, with no clear relationship between mediator concentration and removal efficiency (Figure 3). This can be attributed to its molecular structure containing substituted isopropyl amine, ethylamine and chlorine groups. The arrangement of these groups around the triazine ring makes it highly resistant to biodegradation (Pereira et al., 2013). VA achieved the highest removal of atrazine (73\%), while interestingly ABTS showed the lowest enhancement. Results here suggest that the radical species generated from VA have a much greater potential to overcome steric hindrances and solubility factors associated with these functional groups. HBT achieved the maximum removal efficiency (i.e., 61\%) at $0.1 \mathrm{mM}$, after which a decline was observed. This relationship is remarkably similar to that of VA which also happens to be an $\mathrm{N}-\mathrm{OH}$ type mediator. The results may suggest that high removal efficiencies can be achieved at a comparatively lower mediator concentration when $\mathrm{N}-\mathrm{OH}$ mediators are used to degrade atrazine.

HBT achieved the greatest naproxen removal of $80 \%$ at the highest mediator concentration (1 $\mathrm{mM}$ ) used. In comparison, the performance of VA (another N-OH type mediator), which showed the highest removal of all other TrOCs, was lower for naproxen. HBT and ABTS were both very efficient even at an intermediate dose of $0.5 \mathrm{mM}$ (72 and $75 \%$ removal, respectively).

Overall the radicals produced by the laccase-catalysed oxidation of ABTS appear to have a greater capacity to degrade oxybenzone, pentachlorophenol and naproxen, whereas degradation of atrazine seems to be conducted more efficiently by the aminoxyl radicals produced by the oxidation of VA. The oxidation mechanism of the ABTS radicals follow an electron transfer pathway (Table 1), which has been shown to be effective at oxidising high redox potential substrates (Kurniawati and Nicell, 2007).

It is noted that Figure 3 is based on data derived from duplicate experiments. A more rigorous statistical comparison would require a larger set of data. However, the available data indeed show the dependence of TrOC removal on mediator concentration, and therefore it could be used to point in the direction of a suitable mediator concentration in further testing. 
313 The mediator type and concentration has a major impact on the practicality and feasibility of 314 using laccase in TrOC degradation. The high cost of mediator compounds restrict the maximum

\section{[FIGURE 3]}

\subsubsection{Effect of incubation time}

A series of tests with incubation period varying from $2-24 \mathrm{~h}$ showed that TrOC degradation was rapid, with the majority of degradation occurring within the initial $2 \mathrm{~h}$ for all mediators (Figure 4). Degradation of TrOCs began to slow down over the next 6 hours, after which, degradation virtually ceased, and only minor improvements were observed in atrazine and pentachlorophenol removal. The rapid degradation at the beginning of the experiment indicates that the mediator was being rapidly oxidised by laccase, which led to a fast production of radical species. The cease of degradation within $8 \mathrm{~h}$ indicates that either laccase or the mediator had been affected. The literature suggests that the free radicals produced by the oxidation of mediator are able to destabilise the enzyme by reacting with the aromatic amino residues on the outer surfaces of the enzyme (Khlifi et al., 2010; Kurniawati and Nicell, 2007). Indeed the rapid degradation of contaminants coincided with a large drop in enzyme activity, indicating that the radical species may have been destabilizing the enzyme molecules (Figure 5). These results are in line with the study by Lloret et al. (2013) who also observed enzyme deactivation correlating with accelerated degradation rates of contaminants, diclofenac and naproxen, during the initial hours of the experiment. This aspect is further discussed in the next section.

\section{[FIGURE 4]}

\subsubsection{Effect of mediator type and concentration on laccase stability}

Enzyme activity was highly impacted by mediator addition (Figure 5). The N-OH type mediators HBT and VA both appeared to be detrimental to enzyme activity at all concentrations tested, although VA destabilised the enzyme faster than HBT. For example, the loss of laccase activity was $71 \%$ and ca. $100 \%$ for HBT and VA, respectively at $0.25 \mathrm{mM}$. The enzyme activity 
reduction was lower for ABTS. Similarly, Lloret et al. (2013) observed that ABTS caused the least enzyme inactivation when ABTS, HBT and VA were compared for their enhancement in removal of naproxen and diclofenac. The difference in the rate of inactivation can be linked to the relative stability of the mediator radicals. Other studies have shown that enzyme stability also depends on the species of fungi used. For example, the mediator SA has been reported to deactivate the laccase from Tramettes trogii (Khlifi et al., 2010), while stabilising laccase from Pycnoporus cinnabarinus (Fillat et al., 2010).

As noted in Section 3.2.2, in accordance with the rapid TrOC removal, in this study laccase inactivation also occurred at a very early stage. Figure 5 shows that HBT, VA and ABTS destabilized laccase by 38, 66 and 70\%, respectively within $2 \mathrm{~h}$ of incubation. This demonstrates that once radicals were generated from oxidation of mediators by laccase, they degraded TrOCs, but at the same time caused laccase deactivation. Although enzyme stability was greatly affected by the mediators, it was compensated by their rapid degradation capacity, eventually achieving significant TrOC degradation. However, the aspect of enzyme inactivation may be particularly important for establishing a continuous treatment process where long-term stability of laccasemediator system is required. Thus, the selection of mediator type and concentration is important for the removal of TrOCs by laccase - mediator systems.

[FIGURE 5]

\subsection{Effluent toxicity}

\section{[TABLE 2]}

In this study, the laccase - mediator systems were assessed for their capacity to enhance TrOC removal efficiency. However, the overall quality of the treated effluent (i.e., toxicity) is also important. A few recent studies have suggested that the radicals formed due to the oxidation of mediators can interact with the vitally important biomolecules and cause toxicity (Kim and Nicell, 2006; Nguyen et al., 2014b). Thus it is essential to evaluate the toxicity of the reaction mixture as it undergoes treatment. Of the three mediators screened based on their high TrOC degradation capacity, the $\mathrm{N}-\mathrm{OH}$ type mediators i.e., HBT and VA decreased the toxicity of the treated effluent, whereas ABTS increased. Compared to the toxicity levels of $3.4 \pm 1.4(n=2)$ and 4.3 rTu for separate solutions of laccase and the TrOCs, respectively, the toxicity of the treated effluent following HBT and VA addition was $2.1 \pm 0.3$ and $3.3 \pm 2.1$ rTU ( $n=2)$, respectively. 
372 This suggests that treatment by HBT and VA did not produce significant amounts of toxic-by 373 products and also that the $\mathrm{N}-\mathrm{OH}$ type radicals generated caused negligible toxicity. This 374 particular observation regarding the $\mathrm{N}-\mathrm{OH}$ type mediators is consistent with that in a previous 375 study (Nguyen et al., 2015), where performance of one of the $\mathrm{N}-\mathrm{OH}$ type mediators used in this 376 study i.e., HBT was compared with SA. Notably, HBT and SA are structurally different (i.e., N-

$377 \mathrm{OH}$ type vs. methoxyphenol type), but both follow the hydrogen atom transfer mechanism to 378 oxidize substrates (Table 1). Despite being a natural mediator, SA showed higher toxicity over 379 the synthetic mediator HBT in the previous study (Nguyen et al., 2015). The results from the current study provides a critical clue to selection of mediators by revealing that another $\mathrm{N}-\mathrm{OH}$ type natural mediator VA, which also follows the hydrogen atom transfer mechanism, enhances TrOC degradation without increasing effluent toxicity. The fact that VA is a natural mediator increases the practical significance of the current findings in terms of formulating an environmentally friendly and effective, yet economical process.

\section{Conclusion}

386 The results here confirm that the substrate spectrum of laccase can be broadened by the addition 387 of redox-mediators, however, the performance of laccase - mediator systems is mediator 388 dependent. Of the seven mediators investigated, HBT, VA and ABTS achieved the highest TrOC 389 removal efficiencies. In particular, ABTS and VA achieved the highest degradation of the 390 phenolic compounds, whereas the non-phenolic compounds were best removed using VA or 391 HBT. This implies that the non-phenolic compounds are more efficiently removed by the N-OH 392 type mediators (i.e., VA and HBT), while removal of the phenolic compounds may depend more on the stability of the radicals and their redox potential. Laccase stability was greatly affected by mediator addition, with VA causing the greatest inactivation, followed by HBT and ABTS. This 395 study also showed that higher concentrations of mediator (HBT and VA) result in faster destabilisation of enzyme, thus smaller doses of mediator are favoured. The benefit of using VA 397 is, however, manifested in the fact that this natural mediator can improve the degradation of both 398 phenolic and non-phenolic TrOCs and does not increase the toxicity of the treated solution - a concern which generally impedes the application of laccase - mediator systems. 
The University of Wollongong (UOW) is thanked for a Career Launch Fellowship to Dr Luong

N. Nguyen. This study was partially funded by the GeoQuEST Research Centre, UOW.

\section{References}

Astolfi, P., Brandi, P., Galli, C., Gentili, P., Gerini, M. F., Greci, L. \& Lanzalunga, O. 2005. New mediators for the enzyme laccase: mechanistic features and selectivity in the oxidation of nonphenolic substrates. New Journal of Chemistry, 29, 1308-1317.

Auriol, M., Filali-Meknassi, Y., Tyagi, R. D. \& Adams, C. D. 2007. Laccase-catalyzed conversion of natural and synthetic hormones from a municipal wastewater. Water Research, 41, 3281-3288.

Baiocco, P., Barreca, A. M., Fabbrini, M., Galli, C. \& Gentili, P. 2003. Promoting laccase activity towards non-phenolic substrates: a mechanistic investigation with some laccase-mediator systems. Organic \& Biomolecular Chemistry, 1, 191-197.

Camarero, S., Ibarra, D., Martínez, M. J. \& Martínez, Á. T. 2005. Lignin-Derived Compounds as Efficient Laccase Mediators for Decolorization of Different Types of Recalcitrant Dyes. Applied and Environmental Microbiology, 71, 1775-1784.

Cañas, A. I. \& Camarero, S. 2010. Laccases and their natural mediators: Biotechnological tools for sustainable eco-friendly processes. Biotechnology Advances, 28, 694-705.

d'Acunzo, F. \& Galli, C. 2003. First evidence of catalytic mediation by phenolic compounds in the laccase-induced oxidation of lignin models. European Journal of Biochemistry, 270, 3634-3640.

Fillat, A., Colom, J. F. \& Vidal, T. 2010. A new approach to the biobleaching of flax pulp with laccase using natural mediators. Bioresource Technology, 101, 4104-4110.

Garcia, H. A., Hoffman, C. M., Kinney, K. A. \& Lawler, D. F. 2011. Laccase-catalyzed oxidation of oxybenzone in municipal wastewater primary effluent. Water Research, 45, 1921-1932.

Gros, M., Cruz-Morato, C., Marco-Urrea, E., Longrée, P., Singer, H., Sarrà, M., Hollender, J., Vicent, T., Rodriguez-Mozaz, S. \& Barceló, D. 2014. Biodegradation of the X-ray contrast agent iopromide and the fluoroquinolone antibiotic ofloxacin by the white rot fungus Trametes versicolor in hospital wastewaters and identification of degradation products. Water Research, 60, 228-241.

Hai, F. I., Tadkaew, N., McDonald, J. A., Khan, S. J. \& Nghiem, L. D. 2011. Is halogen content the most important factor in the removal of halogenated trace organics by MBR treatment? Bioresource Technology, 102, 6299-6303.

Hai, F. I., Nghiem, L. D. \& Modin, O. 2013. Biocatalytic membrane reactors for the removal of recalcitrant and emerging pollutants from wastewater. Handbook of Membrane Reactors, Volume 2, (ed. Basile, A.), Woodhead publishing, UK, 2013 (ISBN: 9780857094155), pp. 763-807.

Hai, F. I., Nghiem, L. D., Khan, S. J., Price, W. E. \& Yamamoto, K. 2014. Wastewater reuse: Removal of emerging trace organic contaminants. In: Hai, F. I., Yamamoto, K. \& Lee, C.-H. (eds.) Membrane Biological Reactors. London (ISBN: 9781780400655): IWA publishing.

Hammel, K. E., Kapich, A. N., Jensen Jr, K. A. \& Ryan, Z. C. 2002. Reactive oxygen species as agents of wood decay by fungi. Enzyme and Microbial Technology, 30, 445-453.

Jeon, J.-R., Murugesan, K., Kim, Y.-M., Kim, E.-J. \& Chang, Y.-S. 2008. Synergistic effect of laccase mediators on pentachlorophenol removal by Ganoderma lucidum laccase. Applied Microbiology and Biotechnology, 81, 783-790.

Khlifi, R., Belbahri, L., Woodward, S., Ellouz, M., Dhouib, A., Sayadi, S. \& Mechichi, T. 2010. Decolourization and detoxification of textile industry wastewater by the laccase-mediator system. Journal of Hazardous Materials, 175, 802-808.

Kim, Y.-J. \& Nicell, J. A. 2006. Laccase-catalysed oxidation of aqueous triclosan. Journal of Chemical Technology \& Biotechnology, 81, 1344-1352. 
Kurniawati, S. \& Nicell, J. A. 2007. Efficacy of mediators for enhancing the laccase-catalyzed oxidation of aqueous phenol. Enzyme and Microbial Technology, 41, 353-361.

Lloret, L., Eibes, G., Lú-Chau, T. A., Moreira, M. T., Feijoo, G. \& Lema, J. M. 2010. Laccase-catalyzed degradation of anti-inflammatories and estrogens. Biochemical Engineering Journal, 51, 124-131.

Lloret, L., Eibes, G., Moreira, M. T., Feijoo, G. \& Lema, J. M. 2013. On the use of a high-redox potential laccase as an alternative for the transformation of non-steroidal anti-inflammatory drugs (NSAIDs). Journal of Molecular Catalysis B: Enzymatic, 97, 233-242.

Luo, Y., Guo, W., Ngo, H. H., Nghiem, L. D., Hai, F. I., Zhang, J., Liang, S. \& Wang, X. C. 2014. A review on the occurrence of micropollutants in the aquatic environment and their fate and removal during wastewater treatment. Science of The Total Environment, 473-474, 619-641.

Majeau, J.-A., Brar, S. K. \& Tyagi, R. D. 2010. Laccases for removal of recalcitrant and emerging pollutants. Bioresource Technology, 101, 2331-2350.

Marco-Urrea, E., Pérez-Trujillo, M., Blánquez, P., Vicent, T. \& Caminal, G. 2010. Biodegradation of the analgesic naproxen by Trametes versicolor and identification of intermediates using HPLCDAD-MS and NMR. Bioresource Technology, 101, 2159-2166.

Mendoza, L., Jonstrup, M., Hatti-Kaul, R. \& Mattiasson, B. 2011. Azo dye decolorization by a laccase/mediator system in a membrane reactor: Enzyme and mediator reusability. Enzyme and Microbial Technology, 49, 478-484.

Mizuno, H., Hirai, H., Kawai, S. \& Nishida, T. 2009. Removal of estrogenic activity of iso-butylparaben and n-butylparaben by laccase in the presence of 1-hydroxybenzotriazole. Biodegradation, 20, 533-539.

Nguyen, L. N., Hai, F. I., Price, W. E., Leusch, F. D. L., Roddick, F., Ngo, H. H., Guo, W., Magram, S. F. \& Nghiem, L. D. 2014a. The effects of mediator and granular activated carbon addition on degradation of trace organic contaminants by an enzymatic membrane reactor. Bioresource Technology, 167, 169-177.

Nguyen, L. N., Hai, F. I., Price, W. E., Kang, J., Leusch, F. D. L., Roddick, F., van de Merwe, J. P., Magram, S. F. \& Nghiem, L. D. 2015. Degradation of a broad spectrum of trace organic contaminants by an enzymatic membrane reactor: Complementary role of membrane retention and enzymatic degradation. International Biodeterioration \& Biodegradation, 99, 115-122.

Nguyen, L. N., Hai, F. I., Yang, S., Kang, J., Leusch, F. D. L., Roddick, F., Price, W. E. \& Nghiem, L. D. 2014b. Removal of pharmaceuticals, steroid hormones, phytoestrogens, UV-filters, industrial chemicals and pesticides by Trametes versicolor: Role of biosorption and biodegradation. International Biodeterioration \& Biodegradation, 88, 169-175.

Pereira, P., Sobral Teixeira RS, de Oliveira MAL, da Silva M \& VS, F.-L. 2013. Optimized Atrazine Degradation by Pleurotus ostreatus INCQS 40310: an Alternative for Impact Reduction of Herbicides Used in Sugarcane Crops. Microbial \& Biochemical Technology, http://dx.doi.org/10.4172/1948-5948.S12-006

Tran, N. H., Urase, T. \& Kusakabe, O. 2010. Biodegradation characteristics of pharmaceutical substances by whole fungal culture Trametes versicolor and its laccase. Journal of Water and Environment Technology, 8, 125-140.

Ullah, M. A., Bedford, C. T. \& Evans, C. S. 2000. Reactions of pentachlorophenol with laccase from Coriolus versicolor. Applied Microbiology and Biotechnology, 53, 230-234.

van de Merwe, J. P. \& Leusch, F. D. L. 2015. A sensitive and high throughput bacterial luminescence assay for assessing aquatic toxicity - the BLT-Screen. Environmental Science Process Impacts, 17, 947-955.

Weng, S.-S., Ku, K.-L. \& Lai, H.-T. 2012. The implication of mediators for enhancement of laccase oxidation of sulfonamide antibiotics. Bioresource Technology, 113, 259-264.

Witayakran, S. \& Ragauskas, A. J. 2009. Synthetic Applications of Laccase in Green Chemistry. Advanced Synthesis \& Catalysis, 351, 1187-1209.

Yang, S., Hai, F. I., Nghiem, L. D., Price, W. E., Roddick, F., Moreira, M. T. \& Magram, S. F. 2013. Understanding the factors controlling the removal of trace organic contaminants by white-rot 
fungi and their lignin modifying enzymes: A critical review. Bioresource Technology, 141, 97108. 


\section{LIST OF FIGURES}

Figure 1: Removal efficiency $(\%)$ of selected TrOCs after $24 \mathrm{~h}$ treatment with laccase and mediators. Mediators were added separately at $1 \mathrm{mM}$ concentration. The error bars represent the standard deviation of duplicate samples. HPI= N-hydroxyphthalimide; TEMPO $=(2,2,6,6-$ tetramethylpiperidin-1-yl)oxy; VAN=vanillin; $\mathrm{SA}=$ syringaldehyde; VA=violuric acid; HBT=1hydroxybenzotriazole (HBT); and ABTS=2,2'-azino-bis(3-ethylbenzothiazoline-6-sulfonic acid) diammonium salt.

Figure 2: Impact of mediator addition on the oxidation reduction (redox) potential and the laccase activity. Mediators were added separately at $1 \mathrm{mM}$ concentration. The error bars represent the standard deviation of duplicate samples.

Figure 3: Effect of mediator concentrations on the TrOC removal. The error bars represent the standard deviation of duplicate samples.

Figure 4: Impact of reaction time on TrOC removal efficiency of laccase and mediators. The error bars represent standard deviation of duplicate samples.

Figure 5: Effect of reaction time and mediator concentrations on the laccase stability. The error bars represent the standard deviation of duplicate samples. 


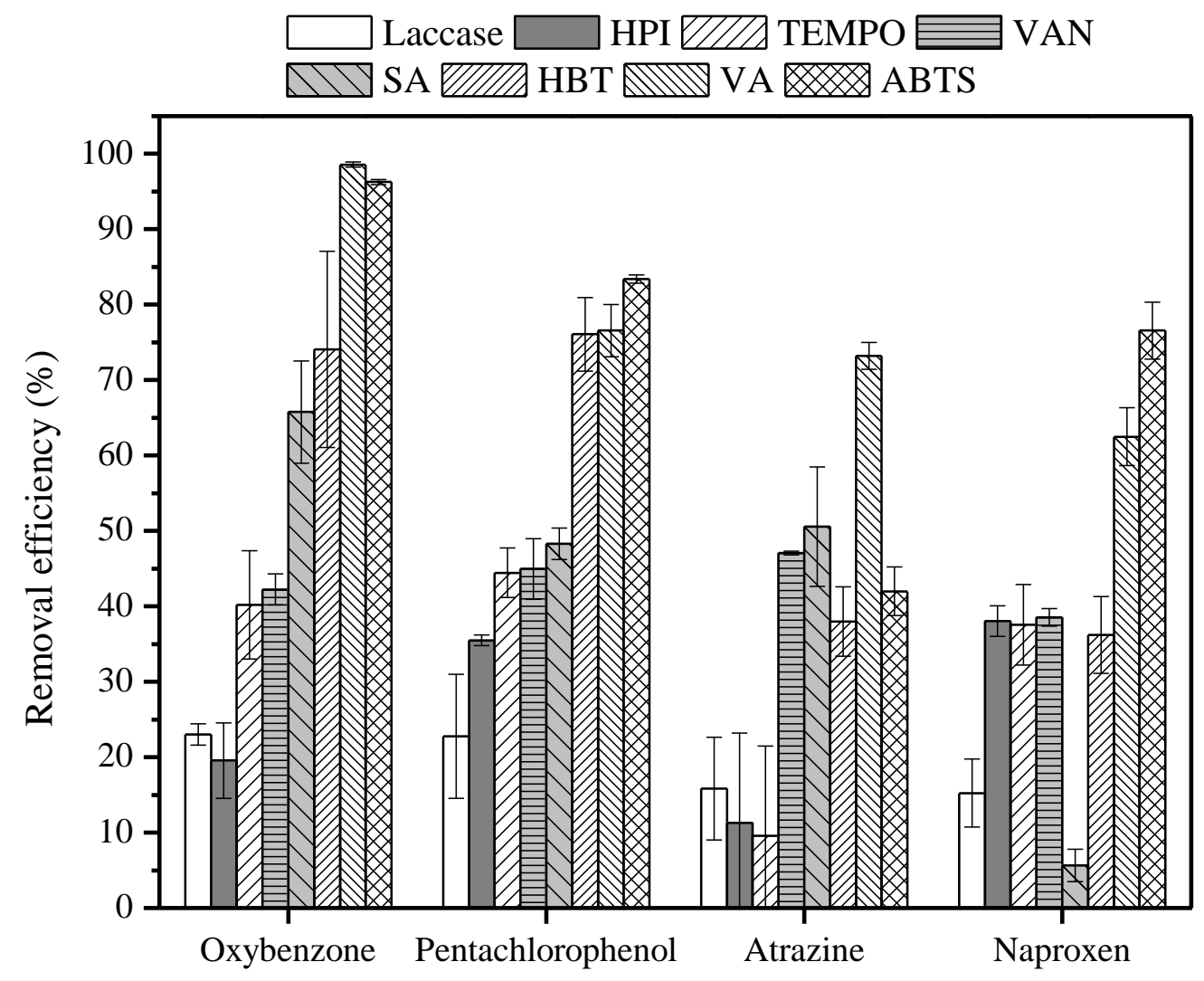

Figure 1: Removal efficiency $(\%)$ of selected TrOCs after $24 \mathrm{~h}$ treatment with laccase and mediators. Mediators were added separately at $1 \mathrm{mM}$ concentration. The error bars represent the standard deviation of duplicate samples. HPI= N-hydroxyphthalimide; TEMPO $=(2,2,6,6-$ tetramethylpiperidin-1-yl)oxy; VAN=vanillin; SA=syringaldehyde; VA=violuric acid; HBT=1hydroxybenzotriazole (HBT); and ABTS=2,2'-azino-bis(3-ethylbenzothiazoline-6-sulfonic acid) diammonium salt. 

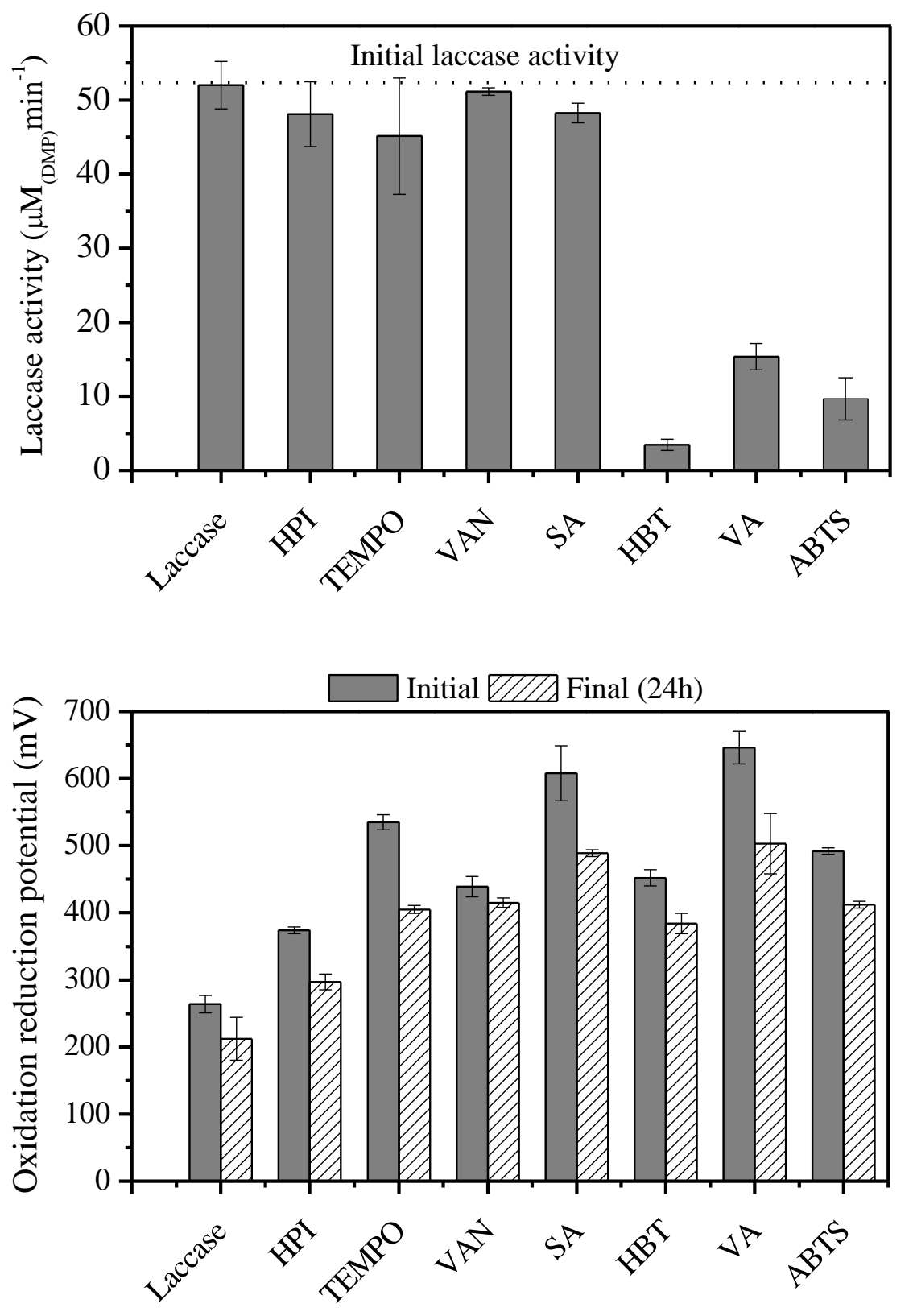

Figure 2: Impact of mediator addition on the oxidation reduction (redox) potential and the laccase activity. Mediators were added separately at $1 \mathrm{mM}$ concentration. The error bars represent the standard deviation of duplicate samples. 


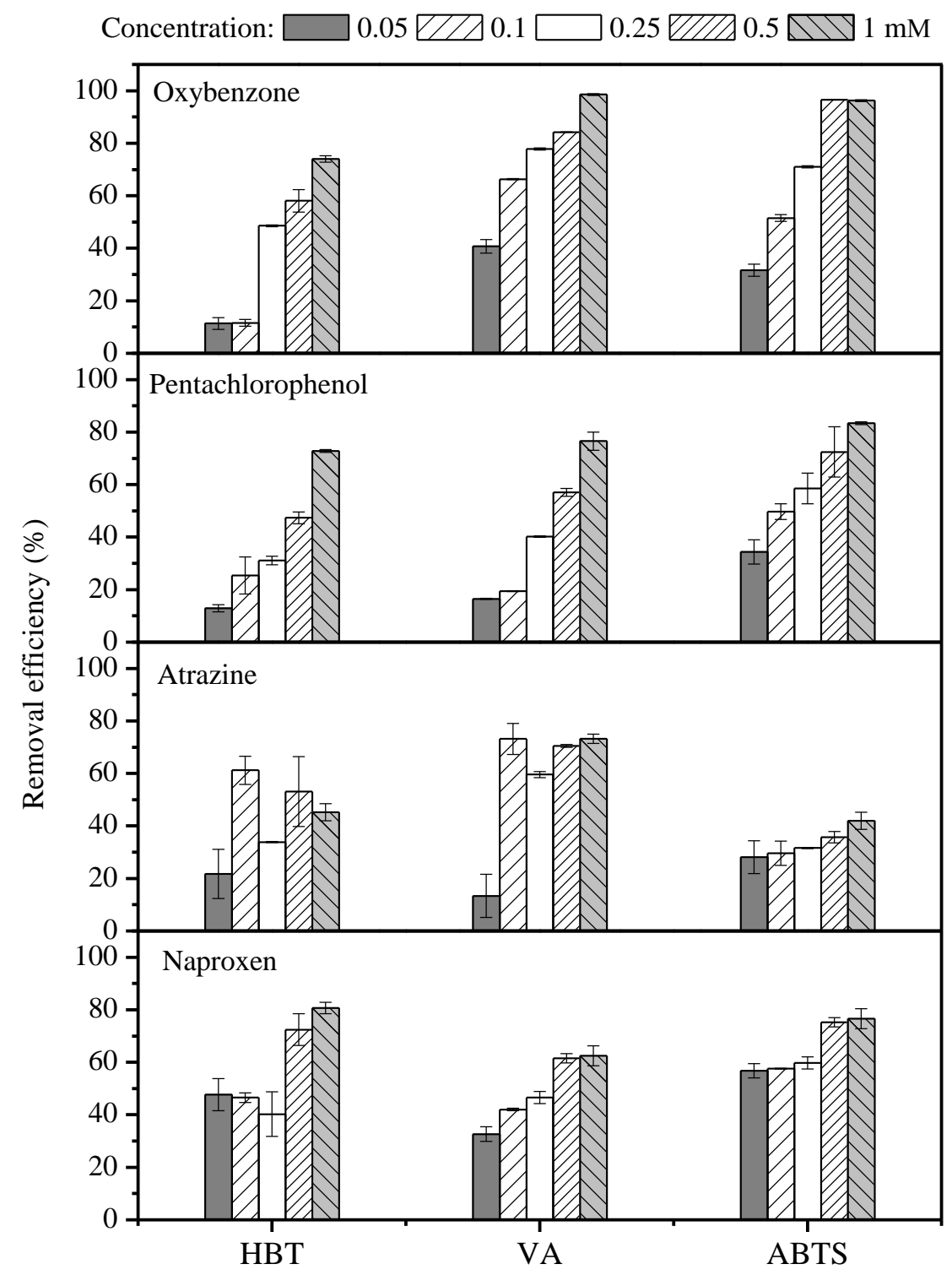

Figure 3: Effect of mediator concentrations on the TrOC removal. The error bars represent the standard deviation of duplicate samples. 


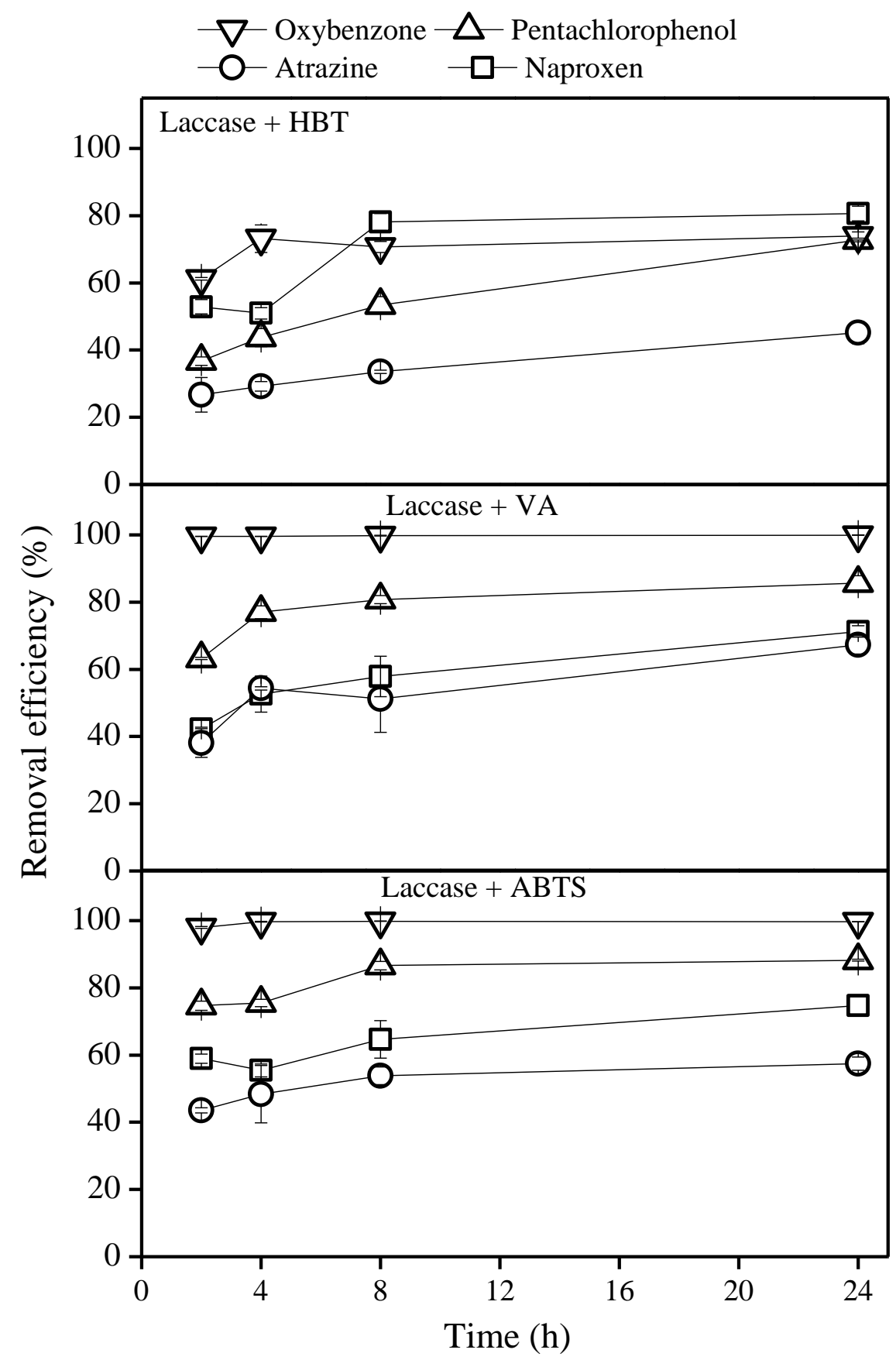

Figure 4: Impact of reaction time on TrOC removal efficiency of laccase and mediators. The error bars represent standard deviation of duplicate samples. 

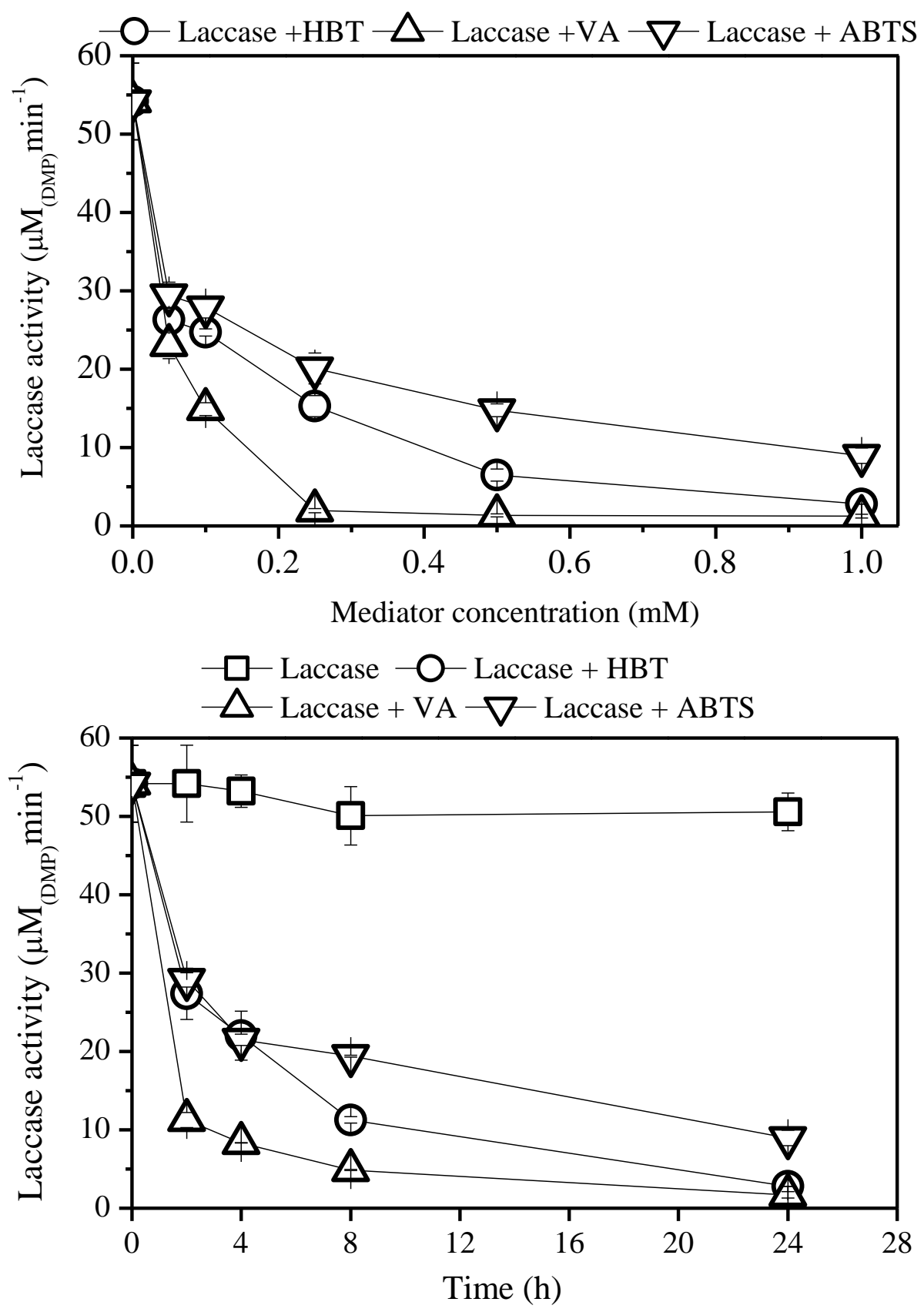

Figure 5: Effect of reaction time and mediator concentrations on the laccase stability. The error bars represent the standard deviation of duplicate samples. 


\section{LIST OF TABLES}

Table 1: Physicochemical properties of the redox-mediators

\begin{tabular}{|c|c|c|c|c|c|}
\hline Redox mediator & Type of mediator & $\begin{array}{c}\text { Free } \\
\text { radical } \\
\text { generated } \\
\end{array}$ & $\begin{array}{l}\text { Oxidation } \\
\text { mechanism }\end{array}$ & Natural/synthetic & Chemical structure \\
\hline $\begin{array}{l}\text { 1-hydroxybenzotriazole } \\
\text { (HBT) }\end{array}$ & $\mathrm{N}-\mathrm{OH}$ & $\begin{array}{c}=\mathrm{N}-\mathrm{O} \\
\text { Aminoxyl }\end{array}$ & HAT & Synthetic & \\
\hline Vanillin (VAN) & $\mathrm{C}_{6} \mathrm{H}_{4}(\mathrm{OH})\left(\mathrm{OCH}_{3}\right)$ & $\begin{array}{c}\mathrm{C}_{6} \mathrm{H}_{5} \mathrm{O} \\
\text { Phenoxyl }\end{array}$ & HAT & Synthetic & \\
\hline $\begin{array}{l}\text { N-hydroxyphthalimide } \\
\text { (HPI) }\end{array}$ & $\mathrm{N}-\mathrm{OH}$ & $\begin{array}{c}=\mathrm{N}-\mathrm{O} \\
\text { Aminoxyl }\end{array}$ & HAT & Synthetic & \\
\hline Violuric acid (VA) & $\mathrm{N}-\mathrm{OH}$ & $\begin{array}{c}=\mathrm{N}-\mathrm{O} \\
\text { Aminoxyl }\end{array}$ & HAT & Natural & \\
\hline Syringaldehyde (SA) & $\mathrm{C}_{6} \mathrm{H}_{4}(\mathrm{OH})\left(\mathrm{OCH}_{3}\right)$ & $\begin{array}{c}\mathrm{C}_{6} \mathrm{H}_{5} \mathrm{O} \\
\text { Phenoxyl }\end{array}$ & HAT & Natural & \\
\hline $\begin{array}{c}2,2,6,6- \\
\text { tetramethylpiperidinylox } \\
\text { yl (TEMPO) }\end{array}$ & $\mathrm{N}-\mathrm{O}^{\circ}$ & $\begin{array}{c}\mathrm{N}=\mathrm{O} \\
\text { Oxoammon } \\
\text { ium }\end{array}$ & Ionic & Synthetic & $\mathrm{CH}_{3}$ \\
\hline $\begin{array}{l}\text { 2,2-azino-nis(3- } \\
\text { ethylbenzothiazoline-6- } \\
\text { sulfnoic acid (ABTS) }\end{array}$ & ABTS & $\begin{array}{l}\text { ABTS+・ } \\
\text { ABTS++ }\end{array}$ & ET & Synthetic & \\
\hline
\end{tabular}

HAT $=$ hydrogen atom transfer, ET $=$ electron transfer and, Ionic $=$ Ionic oxidation 
Table 2: Comparison of toxicity following laccase treatment of TrOCs with different mediators. Mediators were added separately at a concentration of $1 \mathrm{mM}$. The limit of detection of the toxicity assay was $10 \%$ inhibition of luminescence (i.e., 1 rTU).

\begin{tabular}{cc}
\hline Reaction mixture & Toxicity $(\mathbf{r T U})(\boldsymbol{n}=\mathbf{2})$ \\
\hline Laccase & $3.4 \pm 1.4$ \\
\hline TrOCs & 4.3 \\
\hline TrOCs + Laccase + ABTS & $8.8 \pm 5.2$ \\
TrOCs + Laccase + HBT & $2.1 \pm 0.3$ \\
TrOCs + Laccase + VA & $3.3 \pm 2.1$ \\
\hline
\end{tabular}


Impacts of redox-mediator type on laccase degradation of trace organic contaminants:

Degradation efficiency, laccase stability and effluent toxicity

\author{
Revised manuscript Submitted to

\section{International Biodeterioration \& Biodegradation (CESE special issue)}

March, 2016

\begin{abstract}
Bradley Ashe ${ }^{\mathrm{a}}$, Luong N. Nguyen ${ }^{\mathrm{a}}$, Faisal I. Hai ${ }^{\mathrm{a}}$, Duu-Jong Lee ${ }^{\mathrm{b}}$, Jason P. van de Merwe ${ }^{\mathrm{c}}$, Frederic D.L. Leusch ${ }^{c}$, William E. Price ${ }^{\mathrm{d}}$, and Long D. Nghiem ${ }^{\mathrm{a}}$
\end{abstract}

${ }^{\text {a }}$ Strategic Water Infrastructure Laboratory, School of Civil, Mining and Environmental Engineering, University of Wollongong (UOW), NSW 2522, Australia

${ }^{\mathrm{b}}$ Department of Chemical Engineering, National Taiwan University, Taipei, Taiwan.

${ }^{c}$ Smart Water Research Centre, Australian Rivers Institute, School of Environment, Griffith University, QLD 4222, Australia

${ }^{\mathrm{d}}$ Strategic Water Infrastructure Laboratory, School of Chemistry, UOW, NSW 2522, Australia

* Corresponding author: Faisal I. Hai, E-mail: faisal@uow.edu.au, Ph: + 61242213054 
Table S1: Physicochemical properties of the selected micropollutants

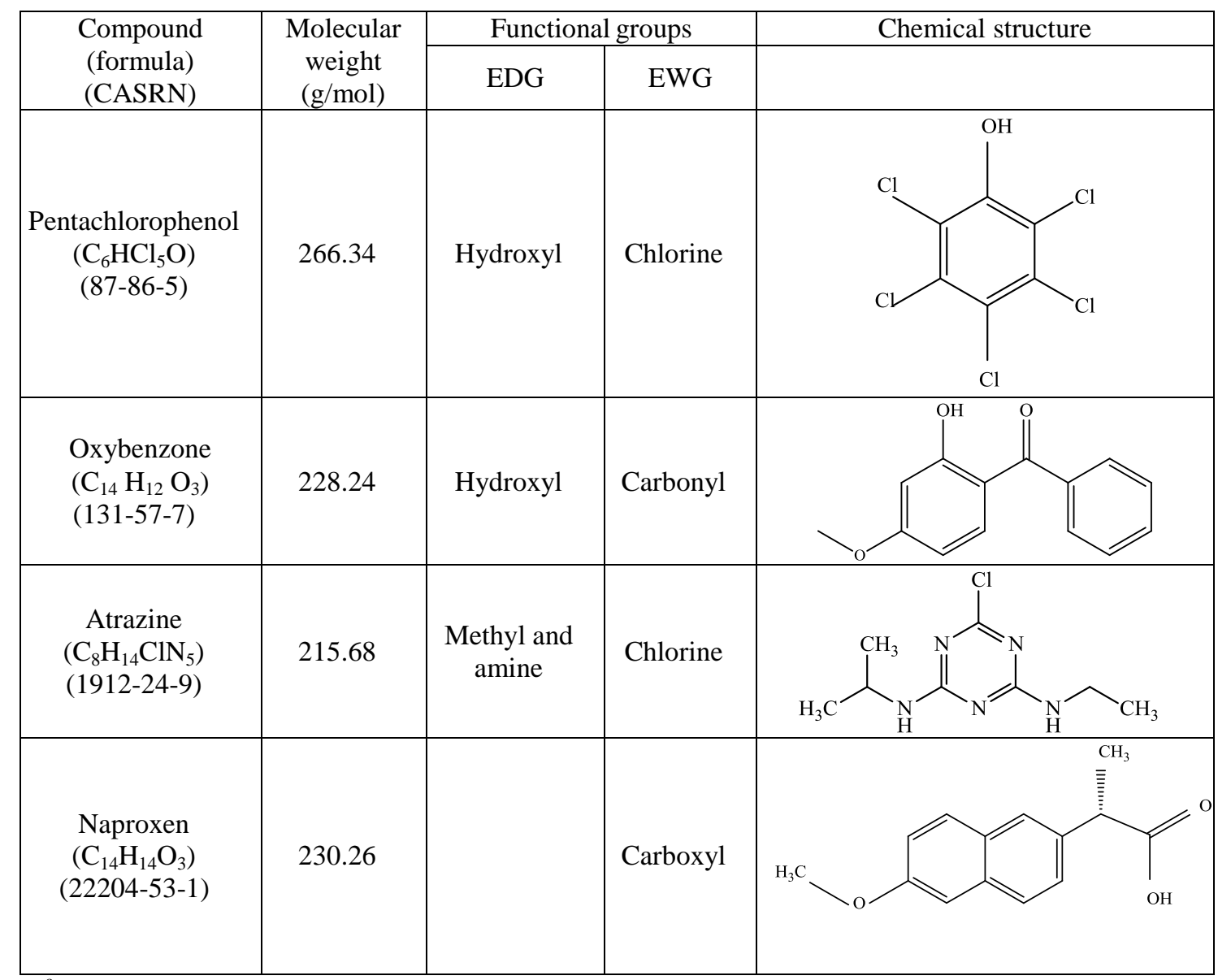

${ }^{a}$ Source: SciFinder database: https://origin-scifinder.cas.org 